\title{
The Online Determination of Bubble Surface Area Flux Using the CiDRA GH-100 Sonar Gas Holdup Meter
}

\author{
Peter A. Amelunxen*, Paul Rothman** \\ *Consultora Amelunxen Mineral Engineering Ltda., Santiago, Chile \\ (Tel: +56-2-321-4218; e-mail: peter@ameltda.com) \\ **CiDRA Minerals Processing, Wallingford, CT, USA \\ (Tel:+1-203-626-3436,e-mail:prothman@cidra.com)
}

\begin{abstract}
In recent years it has been well documented that the bubble surface area flux plays a fundamental role in the performance of industrial flotation machines. Modern instrumentation is not yet capable of providing a robust direct measurement of this parameter, and the widespread industrial use of the available indirect methods have been hampered by the limitations of the available instruments and the complexity of the required calculations. This paper describes a reliable and maintenance-free method for online inference of bubble diameter and bubble surface area flux using CiDRA's GH-100 gas holdup meter. A method is presented for coding the iterative drift-flux analysis calculations for column cell bubble diameter and surface area flux using standard expert system or DCS programming language. An alternative empirical method applicable to mechanical cells is also demonstrated. Operating data from an industrial plant historian is presented.
\end{abstract}

Keywords: flotation, process control, bubble surface area flux, gas holdup

\section{INTRODUCTION}

It is well established that the bubble surface area flux $\left(\mathrm{S}_{\mathrm{b}}\right)$ plays a key roll in the flotation efficiency of a column or mechanical cell (Gorain et al. 1997). The apparent linear or near-linear relationship between $S_{b}$ and collection zone first order rate constant $(\mathrm{k})$ has been documented (Deglon et al., 1999) and debated (Heiskanen 2000). While there is some discussion regarding the nature and extent of the relationship between $\mathrm{S}_{\mathrm{b}}$ and rate constant, there is little debating the overall importance of the parameter in characterizing the flotation process. An example of one such published relationship is illustrated in Figure 1.

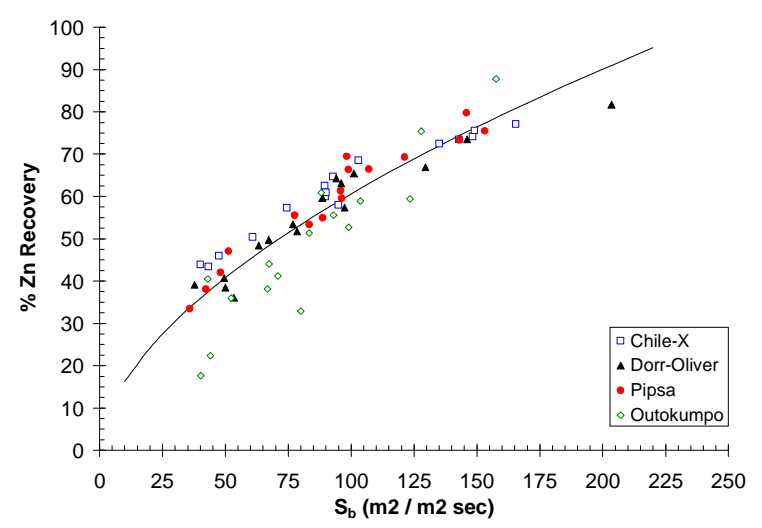

Fig. 1 - Bubble surface area flux versus zinc recovery (after Gorain et al., 1997)
Because modern instrumentation is not yet capable of measuring the $\mathrm{Sb}$ directly, researchers and plant operators have resorted to inferring the value of $S_{b}$ from other, measureable, parameters. One approach involves measuring the Sauter mean bubble diameter $\left(\mathrm{d}_{\mathrm{b}}\right)$ and calculating the $\mathrm{S}_{\mathrm{b}}$ from the superficial gas velocity $\left(\mathrm{J}_{\mathrm{g}}\right)$ using Equation 1 (e.g. Schwarz \& Alexander, 2005).

$S_{b}=\frac{6 J_{g}}{d_{b}}$

Another approach involves measuring the gas holdup ( $\left.E_{g}\right)$ and calculating the $\mathrm{S}_{\mathrm{b}}$ from the superficial velocities of the air and slurry fractions using drift-flux analysis (e.g. Dobby et al. 1988).

A third approach, typically reserved for offline applications, consists of an empirical relationship between various machine design and operating parameters including Jg and flotation cell feed P80 (Gorain et al. 1999). This method will not be discussed further herein.

While each of these methods provides valuable diagnostic information for offline process modelling and optimization, their widespread adoption for online process control has encountered resistance, primarily for the reasons discussed below. 


\subsection{Bubble diameter $\left(d_{b}\right)$ measurement}

The two predominant instruments for online measurement of bubble size analyzer are the UCT bubble size analyzer and the McGill camera imaging method.

The McGill bubble viewer consists of a PVC sampling tube that samples bubbles from the flotation cell pulp and directs them into an illuminated water-filled viewing chamber where a high speed video recorder captures the image and digital imaging technology is used to determine the bubble size distribution, from which the Sauter mean diameter is calculated. The main limitation for online applications involves cleaning the viewing chamber, as the bubbles carry solid particles that are released when the bubbles burst at the top of the viewing chamber (Chen et al. 2001).

The UCT bubble size analyzer consists of a capillary tube that is immersed in the pulp and captures the bubbles. As the bubbles migrate through the capillary tube they pass through an optical detector that measures the length of the bubble, and the bubble size is calculated from the volume (Tucker et al., 1994). Practical limitations to online applications include the size of the capillary tube, which is thought to produce a bias towards smaller bubble diameters (Hernandez-Aguilar et al., 2004), and the procedures required to normalize the bubble volume for film thickness on the walls of the capillary, which changes with the chemistry of the water (Tucker et al., 1994).

\subsection{Gas holdup measurement}

The traditional method for inferring gas holdup is through differential pressure measurements, typically on column cells. The gas holdup is calculated from the pulp density and the pressure difference across a known distance. This method is prone to significant error due to the variations in pulp density that results from changing mineral assays and solids concentrations, and it is primarily for this reason that researchers have sought more precise methods for directly measuring the gas holdup.

To date, the most promising alternative is the McGill conductivity probe, which consists of two cylinders (cells) one open at both ends which measures the aerated slurry conductivity and a second with a restricted opening at the bottom which sets up a siphon effect and enables the deaerated slurry conductivity to be measured. The ratio of the two conductivities is substituted in Maxwell's model for a non conducting dispersed phase (i.e., bubbles in this case) in a continuous conducting phase (i.e., slurry in this case). While the sensor provides very accurate gas holdup measurements, perceived limitations include the build-up of scale on the electrodes and the plugging of the siphon cell, although recent design modifications are reported to have mitigated the latter (Gomez et al., 2003).

\section{GH-100 METER}

The GH-100 is a sonar-based gas holdup meter designed to be submersed in a three-phase slurry and to withstand the demands of harsh industrial processes. The meter utilizes
CiDRA's patented SONARtrac technology which uses passive listening techniques first developed for underwater sonar applications to measure the speed at which naturally occurring sound propagates within the aerated pulp. The propagation velocity provides an accurate and robust measurement of the gas holdup on a real time basis.

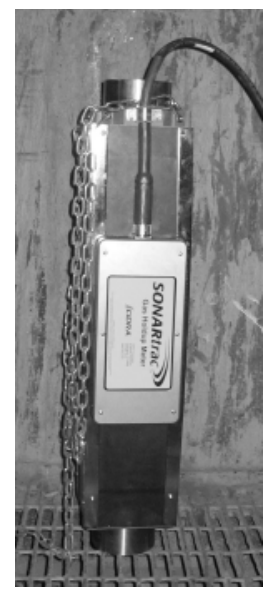

Fig. 2 - Gas holdup meter

The meter (Fig. 2) consists of a cylinder, open at both ends, with an axial array of non-process-wetted sensors. The sensors are mounted on the outside of the cylinder and protected from the process mixture with a sealed environmental enclosure. With the cylinder vertically mounted, the slurry is free to flow through the sensor without restriction. Naturally occurring acoustic waves travel in both directions through the cylinder. The meter senses these disturbances and characterizes the speed at which the coherent waves pass through the array using beam-forming techniques developed over several decades of applications.

With the sound speed propagation velocity of the mixture, and a basic understanding of the slurry properties, the gas holdup can be determined. The relationship between the speed of sound in a two-phase mixture and the phase fraction is well established for mixtures in which the wavelength of the sound is significantly larger than the bubbles in the flow. Therefore, the sound speed of a mixture can be related to the volumetric phase fraction $\left(\varepsilon_{\mathrm{i}}\right)$ of the components and the sound speed $\left(a_{\mathrm{i}}\right)$ and densities $\left(\rho_{\mathrm{i}}\right)$ of the components through the following relationship:

$\frac{1}{\rho_{\text {mix }} a_{\text {mix }}^{2}}=\sum_{i=1}^{N} \frac{\varepsilon_{i}}{\rho_{i} a_{i}^{2}}$

where

$\rho_{\text {mix }}=\sum_{i=1}^{N} \rho_{i} \varepsilon_{i}$

The GH-100 was designed to be used as an industrial tool to measure gas holdup in slurry on a real time basis. The unit is impervious to scale build-up and the fundamental operating principles are well suited for making this measurement within an aerated pulp. Flotation is an ideal application of the technology, and trials in various plant operating 
environments have been very successful. In one case the meter has operated maintenance-free for more than five years in an industrial column cell.

\section{ONLINE BUBBLE SURFACE AREA FLUX CALCULATIONS}

This section reviews two methods for calculating the bubble surface area flux using the online gas holdup measurements from the GH-100. The first method uses drift flux analysis and the second relies on empirical correlation between gas holdup and bubble surface area flux. Both methods can be used for either column cells or mechanical cells.

\subsection{Drift flux analysis method}

Although there are several alternative methods, the bubble diameter and bubble surface area flux calculations chosen for this example employ the re-derived iterative method of $\mathrm{Xu}$ and Finch (after Banisi and Finch, 1994). The drift flux equations are briefly reviewed below.

The slip velocity of gas and liquid in counter-current systems is given by

$U_{s b}=\frac{J_{g}}{\varepsilon_{g}}+\frac{J_{l}}{1-\varepsilon_{g}}$

where $\mathrm{J}_{\mathrm{g}}$ and $\mathrm{J}_{\mathrm{l}}$ are the superficial velocities of gas and slurry, respectively and $\varepsilon_{\mathrm{g}}$ is the gas holdup. The terminal rise velocity of a bubble in an infinite pool $\left(\mathrm{U}_{\mathrm{T}}\right)$ is related to the slip velocity $\left(\mathrm{U}_{\mathrm{sb}}\right)$ by the general equation

$U_{T}=\frac{U_{s b}}{\left(1-\varepsilon_{g}\right)^{m-1}}$

where $\mathrm{m}$ can be assumed constant with a value of 3.0. A mean bubble diameter $\left(d_{b}\right)$ is then calculated from the terminal rise velocity:

$d_{b}=\sqrt{\frac{18 \mu_{f} U_{T}}{g\left(\rho_{f}-\rho_{a}\right)}\left(1+0.15 \operatorname{Re}_{b}{ }^{0.687}\right)}$

where the Reynolds number of the bubble swarm, $\operatorname{Re}_{b}$, is given by

$$
\operatorname{Re}_{b}=\frac{d_{b} U_{s b} \rho_{f}\left(1-\varepsilon_{g}\right)}{\mu_{f}}
$$

and $\rho_{\mathrm{f}}$ is the pulp density and $\mu_{\mathrm{f}}$ is the pulp viscosity. Note that the calculation of the Reynolds number requires knowledge of the bubble diameter, yet the bubble diameter can not be calculated without knowing the Reynolds number. Hence, an iterative procedure is used. The procedure is:

1. Assume an initial bubble diameter $\mathrm{d}_{\mathrm{b}}=0.1 \mathrm{~cm}$

2. Calculate $U_{\mathrm{sb}}$ from Equation 4

3. Calculate $\mathrm{U}_{\mathrm{T}}$ using Equation 5

4. Calculate the Reynolds' number using Equation 7
5. Calculate the new bubble diameter using Equation 6

6. Repeat steps $1-5$ until the bubble diameter converges

This kind of iterative procedure can be very easily programmed into almost any process control architecture that allows looping, such as Gensym's G2 architecture, Knowledgscape, and most commercially available DCS systems. The resulting algorithm yields an online measurement of bubble diameter and bubble surface area flux (from equation 1), which can then be recorded in the data historian (for offline diagnostics, troubleshooting, and maintenance optimization) or used for online process control.

Figures 3 and 4 show calculated bubble diameter and surface area flux values from an industrial cleaner column cell over an arbitrary four day period. For this particular application measurements were taken at 15-second intervals and no smoothing was applied.

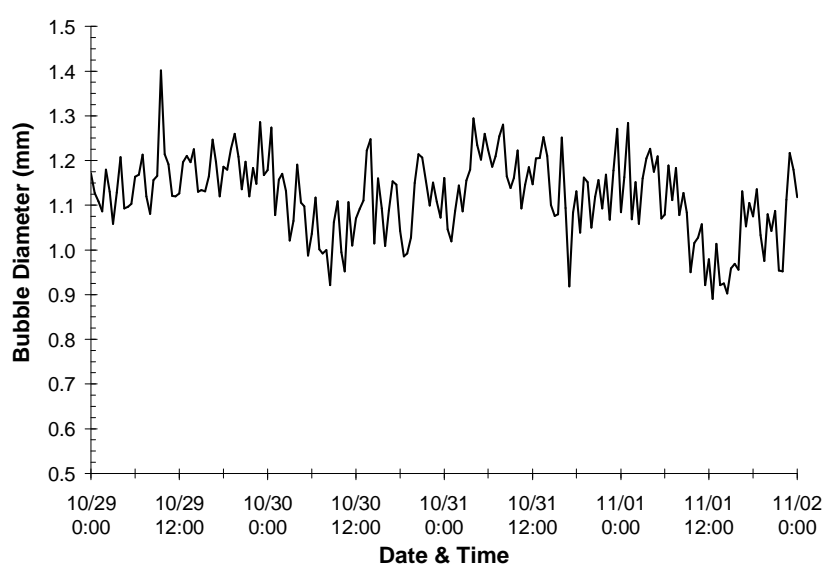

Fig. 3 - Historized bubble diameter from an industrial application

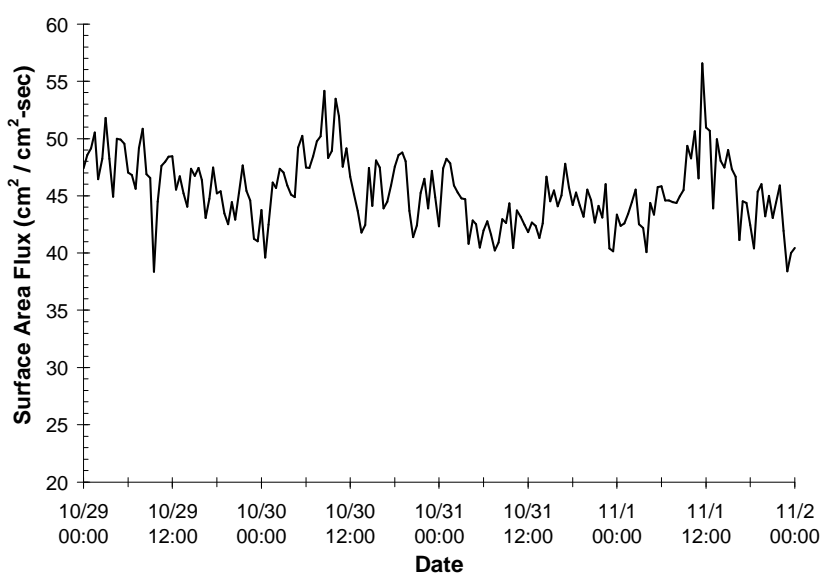

Fig. 4 - Historized bubble surface area flux from an industrial application

\subsection{Empirical method}

Finch et al. (2000) investigated the relationship between gas holdup and $\mathrm{S}_{\mathrm{b}}$ using cell operating data collected from 
published research, finding that the $\mathrm{S}_{\mathrm{b}}$ can be approximated from gas holdup using the following empirical relationship:

$$
S_{b} \approx 5.5 \varepsilon_{g}
$$

Substituting equation 8 into Equation 1 yields the following empirical approximation of bubble diameter:

$$
d_{b} \approx \frac{1.091 J_{g}}{\varepsilon_{g}}
$$

These relationships are deemed accurate for typical values of gas holdup and area flux. Note that both methods require knowledge of the air rate $\left(\mathrm{J}_{\mathrm{g}}\right)$ to the flotation cell. For column cells this can be accomplished by using mass flow meters on the sparger feed lines. For mechanical cells this can be accomplished by using an air velocity measurement device on the cell aspiration pipe.

\subsection{Limitations of calculation methods}

It should be noted at this point that both of the methods discussed above have some inherent limitations to the accuracy and precision of the resulting $\mathrm{d}_{\mathrm{b}}$ and $\mathrm{S}_{\mathrm{b}}$ values. For example, it is has been reported that the relationship between gas holdup, gas rate, and bubble size defined by the drift flux equations are specific to the frother type and the electrolyte concentration of the water phase (Azgomi et al., 2007). The empirical method of Finch et al. does not have a pulp density and viscosity component, and this likely introduces error in the inferred $d_{b}$ and $S_{b}$ values. The GH-100 is based on the speed of sound, hence the sensitivity decreases as the gas holdup increases, resulting in an effective operating range of up to approximately $20 \%$ gas holdup. Finally, it is known that significant differences can exist between gas holdup values measured at different points in a cell cross section. Nevertheless, because the process control strategies described below are based primarily on the rate of change of the bubble diameter and surface area flux, rather than their absolute values, these limitations are not thought to be significant for the purposes of the process control strategy suggested below.

\section{PROCESS CONTROL STRATEGIES}

The process control strategies proposed herein consist of two main objectives:

1. Maximize stage metal recovery by increasing bubble surface area flux (i.e. moving right along the $\mathrm{x}$-axis of Figure 1). This can be done either by

\section{a. Controlling frother to minimize bubble diameter \\ b. Controlling gas flow rate (if possible)}

2. Optimize frother consumption by ensuring that the plant never operates above the critical coalescence concentration, or CCC, (Cho and Laskowski, 2002) for the given plant conditions.

An example of the process control strategy can be illustrated graphically using the curve of frother concentration versus bubble size (Fig. 5). The points shown are from Finch et al. 2008 for a fixed condition (MIBC in water), but the plant curve is likely dynamic, shifting along both vertical and horizontal axes based on changing plant variables such as flotation feed size, concentration of electrolytes in the plant water, $\mathrm{pH}$, the concentration of frother in the reclaim water, and circulating pulp volumes. Note that "fother concentration" as used in Fig. 5 (and hereafter) is defined as the unit frother addition rate per tonne of water flow rate in the pulp (ppm). Due to differences in reclaim water ratios, plant circulating loads, and useful lives of frothing agents, it is not possible at the plant scale to ascertain with confidence the true concentration of frother in the flotation pulp (although a recently developed method suited to on-site determination may help resolve the problem (Gelinas and Finch, 2007)).

The plant position shown in Fig. 5 can be calculated by measuring the changes in $\mathrm{d}_{\mathrm{b}}$ and calculated frother concentration over time, yielding the slope of the curve at the plant operating point over the given time interval. If the slope is slightly negative or zero (Plant Position 2 in Fig. 5), then frother dosage can likely be reduced without affecting metallurgical performance. If the slope is strongly negative (Plant Position 1), it is likely that the plant is operating below the critical coalescence point and that increasing frother dosage would yield improved recoveries, frothing and downstream constraints permitting. The algorithm is simple and straightforward; in fact, it is virtually identical to traditional expert system algorithms used for optimizing the power and load in a SAG mill (e.g. Whitford \& Sloan, 2001).

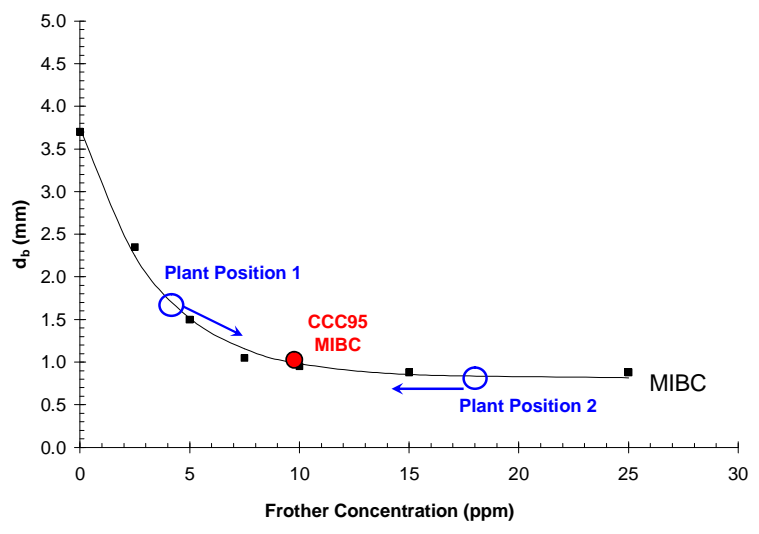

Fig. 5 - Bubble size versus MIBC concentration for air in water (after Finch et al., 2008.)

The proposed control strategy would offer the following benefits when correctly applied in plant flotation circuit.

1. Improved metallurgical performance by quickly reacting to changes in ore type or water chemistry that may lead to sub-optimal frothing characteristics and reduced bubble surface area flux in the flotation pulp.

2. Cost savings associated with reducing excessive frother consumption. Large concentrators often spend more than $\$ 1$ million per year on frother consumption, and 
achieving even a small reduction would quickly pay back the cost of the instrumentation.

3. Metallurgical benefits associated with reducing frother consumption; i.e. reduced frothing problems in downstream operations such as concentrate pumping, water reclaim operations, and copper/moly separation.

Note that the above strategy does not consider froth bed stability. It is conceivable that in some cases the optimal frother dosage point from the perspective of maintaining a stable froth bed is higher than the CCC of the frother in the flotation pulp. In this situation, it could be argued, the cost savings benefit (Item 2, above) would no longer apply. However, the authors would argue that because each frother has a unique relationship between bubble formation and froth stability, in such a situation the process plant is likely using the wrong frother. Conveniently, the GH-100 generates the data (gas holdup) required for choosing an alternative, using the framework proposed by Cappuccitti and Finch (2009).

\section{CONCLUSIONS}

This paper has shown that the CiDRA GH-100 is a mechanically robust and maintenance-free instrument for providing online values of gas holdup, bubble diameter and bubble surface area flux in a plant environment. A method for integrating the output of the CiDRA probe into standard process control software has been detailed and examples from a plant scale column cell have been provided. A simple control strategy based on frother set point control has been proposed.

\section{ACKNOWLEDGEMENTS}

The authors would like to thank CiDRA Minerals Processing for permission to use GH-100 data and to publish this paper.

Thanks also to Prof. James Finch at McGill University for the input and comments.

\section{REFERENCES}

Azgomi, F., Gomez, C.O., and Finch, J.A., “Correspondence of gas holdup and bubble size in presence of different frothers,” Int. J. Miner. Process. 83 (2007) 1-11

Banisi, S., and Finch, J.A., "Technical Note - Reconciliation of bubble size estimation methods using drift flux analysis,” Minerals Engineering, Vol. 7, No. 12, pp 15551559, 1994.

Cappuccitti, F., and Finch, J.A., "Characterization of frothers and its role in flotation optimization,", Proceedings of the 2009 SME Annual Meeting, 2009, Denver, Colorado.

Chen, F, Gomez, C O and Finch, J A, 2001. Technical note: bubble size measurement in flotation machines, Minerals Engineering, 14(4):427-432.

Cho, Y. S. and Laskowski, J. S. 2002. Effect of frothers on bubble size and foam stability, Int. J. Miner. Process. 64: 69-80.

Deglon, D.A., Sawyerr, F., and O’Connor, C.T., 1999. “A model to relate the flotation rate constant and the bubble surface area flux in mechanical flotation cells," Minerals Engineering Vol. 12, No.6, pp 599-608.

Dobby, G.S., Yianatos, I.B. \& Finch, I.A., Estimation of Bubble Diameter in Flotation Columns from Drift Flux Analysis, Canadian Metallurgical Quarterly, 27, 2, pp 85-90, 1988.

Finch, J.A., Xiao, J., Hardie, C., and Gomez, C.O., "Gas dispersion properties: bubble surface area flux and gas holdup," Minerals Engineering Vol. 13, No. 4, pp 365372, 2000

Finch, J.A., Nesset, J.E, and Acuña, C., "Role of frother on bubble production and behaviour in flotation,", Minerals Engineering 21 (2008), pp 949-957

Gélinas, S. and J. A. Finch, Frother Analysis: Some Plant Experiences, Minerals Engineering, Vol. 20, pp. 13031308 (2007)

Gomez, C.O., Cortes-Lopez, F., and Finch, J.A., Industrial testing of a gas holdup sensor for flotation systems, Mineral Engineering 16 (2003) 493-501

Gorain, B.K., Franzidis, J.P, and Manlapig, E.V., 1997 "Studies on impeller type, impeller speed, and air flow rate in an industrial scale flotation cell. Part 4: effect of bubble surface area flux on flotation performance”, Minerals Engineering, vol. 10, No 4., pp 367-379.

Gorain, B K, Franzidis, J P and Manlapig, E V, 1999. The empirical prediction of bubble surface area flux in mechanical flotation cells from cell design and operating data, Minerals Engineering, 12(3):309-322.

Heiskanen, K. 2000. "On the relationship between flotation rate and bubble surface area flux". Minerals Engineering, 13: 141-149.

Hernandez-Aguilar, J R, Coleman, R G, Gomez, C O and Finch, J A, 2004. A comparison between capillary and imaging techniques for sizing bubbles in flotation systems, Minerals Engineering, 17(1):53-61.

Schwarz, S, and Alexander, D., "Gas dispersion measurements in industrial flotation cells" Centenary of Flotation Symposium, Brisbane, 2005.

Tucker, J P, Deglon, D A, Franzidis, J P, Harris, M G and O'Connor, C T,1994. An evolution of a direct method of bubble size distribution measurement in a laboratory batch flotation cell, Minerals Engineering, 7(5/6):667680 .

Whitford, A., and Sloan, R., "Innovative solutions in the development of an expert system at CCI's Empire Mine," Proceedings of the 2001 SME Annual Meeting, 2001, Denver, Colorado. 